\title{
Early Australian implement variation: a reduction model
}

\author{
Peter Hiscock \\ Australian National University, Australia
}

\author{
Val Attenbrow
}

Australian Museum, Australia

\section{(Received 25 January, revised manuscript accepted 5 March)}

\begin{abstract}
The composition of lithic assemblages is typically depicted in terms the relative abundance of different implement types. In this paper we hypothesize that the characteristics of early Australian assemblages said to distinguish those types are part of a morphological continuum, and that this continuum is largely explained as a reflection of different levels of reduction. We demonstrate the viability of this perspective at one of the classic sites at which early industries were defined, Capertee 3. The existence of an Australian technology structured around continuous reduction without evidence of "imposed form" reveals that this pattern is widespread and should not be taken to represent an "archaic" approach to stone working. Implications for conventional interpretations of Palaeolithic stone implements are briefly examined.

(C) 2002 Elsevier Science Ltd. All rights reserved.
\end{abstract}

\section{Keywords: LITHICS, REDUCTION, TYPOLOGY, AUSTRALIA.}

\section{Introduction}

M orphological variation in assemblages of stone artefacts has traditionally been presumed to be discontinuous, each morphological "type" reflecting the design of a functionally specific tool. In various guises this approach has dominated studies of Palaeolithic assemblages and is embedded within typological practice (Hiscock, 2002). Alternative images focusing on the reduction processes creating these types have long been advocated (e.g. Geneste, 1989; Holmes 1890; Leroi-Gourhan, 1956, 1966; Wheat, 1976). Over the last two decades this reduction-oriented approach has increasingly challenged typological models by suggesting morphological variability often occurs as a continuum rather than as discrete types. In recent years this argument has been strongly advanced by the quantitative analyses of what we could term the "Philadelphia School" (e.g. Dibble, 1984, 1987, 1995; Holdaway et al., 1996; McPherron, 1994, 2000), but has also been developed in other formats (e.g. Gordon, 1993; Hiscock, 1996; Kuhn, 1992, 1995). These analyses have proved invaluable in offering an alternative depiction of European Palaeolithic variability (see Odell, 2000: 286-287). Such models share as their central feature the proposition that the continuous variation in morphology reflects different stages in a continuous reduction process. A relationship between morphological transformations and extent of reduction has been demonstrated for a number of Middle and Lower Palaeolithic assemblages, and has occasionally been identified in later assemblages in the Old World (e.g. Neeley \& Barton, 1994) and biface assemblages in North America (e.g. Flenniken, 1985; Wheat, 1976). However, these characterizations have been rare in other regions and time periods, inhibiting general statements about the structure and evolution of these forms of lithic variability. As a means of addressing this dearth of reduction studies this paper contributes the first study of this kind from Australia. Testing a reduction model for early assemblages in a continent colonized by modern humans provides an opportunity to characterize the extent to which morphological transformation typifies the lithic assemblages created by modern hunter-gatherers.

More importantly, the application of reduction models has typically incorporated procedures that are neither central to their development nor entirely helpful in depicting what is often interpreted as a continuous flaking process. For instance, analyses seeking to illustrate morphological continuums have often been grounded in measurements of typological classes, a practice that relies on comparisons of type categories while attempting to reveal that such categories are arbitrary and cumbersome descriptions of continuous variation. Furthermore, because conventional typological classes were not constructed to depict reduction 
a continued reliance on those categories risks reifying rather than testing the typological framework. Since a number of quantitative indices measuring reduction are available now (e.g. Barton, 1988; Clarkson, 2002; Kuhn, 1990) it is not necessary to persist in using typological categories in this way. Of course some reduction models have been based on a typology simply to demonstrate that conventional types are simply arbitrary categories imposed on morphological variation. However, other aspects of previous reduction studies reveal typological presumptions. For example, the retouched flakes are presumed to be tools, and the continued reduction is typically explained as maintenance of the working edge. In this paper we seek to test whether or not morphological variation in Australian implements is continuous, and whether that variation is explicable in terms of the extent of reduction, while emphasizing continuous measures and without assuming the role of the flaking. After illustrating how this can be done we will return to the possible implications for interpretations of assemblage variation.

\section{Variation in Early Australian Assemblages}

For that period in Australia prior to the appearance of backed artefacts and bifacial points, archaeologists have typically characterized lithic assemblages in terms of cores and dorsally retouched flakes that were labeled by typologists as "scrapers". The now defunct description of these "early" assemblages as the "Core Tool and Scraper Tradition" reflected that characterization (Hiscock \& Allen, 2000). As has happened in other parts of the world, Australian archaeologists have looked at the morphological and size variation between such specimens as a reflection of different functional designs, constructing classifications of different types of implements as a way of depicting the perceived variation.

Many examples illustrate this general approach. For instance, in their influential discussion of the Pleistocene assemblages of Lake Mungo, Rhys Jones and Harry Allen divided the implements into "steep edge scrapers", "flat scrapers", "multiple concave scrapers", and core tools (Bowler et al., 1970). Based on the shape and steepness of the retouched edges they suggested different functions for each type. For other early assemblages divisions of "scrapers" into types using the shape, disposition and extent of retouched edges yielded categories such as "side scraper", or "side-side-and-end scraper" (Lampert, 1971: 20), "round edge scrapers", "flat straight scrapers", "notched scrapers", and "concave and nosed scrapers" (Jones, 1977; Bowdler, 1981), or "side scrapers", "double side scrapers" and "concave side scrapers" (Clegg, 1977). The relative abundance of specimens assigned to each of these classes was taken to be an indication of the nature of activities carried out in a site or level, paralleling the logic of functional interpretations of assemblage variation seen elsewhere in the world. Even recent syntheses advocate the value of these kinds of categories and principles. Take for example the discussion by Mulvaney \& Kamminga (1999: 217-219, 227) of Pleistocene Australian implements which defines categories such as "end scraper", "straight-edged scrapers", "notched scrapers" "concave scrapers", "nosed scrapers", "Gamberian discoids" and "thumbnail scrapers". To each category they attribute a different functional design, and although they accept that notched and concave forms may be part of a continuum as resharpening proceeds, the other forms are considered typologically and functionally distinctive. All of these examples apply a similar typological approach, partly because they are all built on the classification systems developed by McCarthy et al. (1946) and Mitchell (1949: 27), and used extensively by McCarthy (McCarthy, 1948, 1949, 1958, 1963, 1964, 1967) and others.

In this paper we hypothesize that differences between the scraper types that have been recognized in Australia may be explained in terms of the extent of knapping each object has undergone. This reduction model posits that morphological change occurs roughly proportional to the amount of retouching that has been applied to a flake, irrespective of whether that retouching was maintaining edges and/or generating flakes. The predictions of such a model are both obvious and common sense. Specimens that have received little retouch will have relatively straight retouched edges, with small retouched scars restricted to a short portion of the flake margin. In contrast specimens that have been extensively retouched will have longer more curving retouched edges, with larger retouch scars spread along much of the flake margins. A model such as this, hypothesizing continuous morphological variation that reflects differences in the amount of reduction, has not previously been proposed in this manner for early Australian assemblages. This is curious, not only because reduction models of this kind have now been shown to be extremely applicable to implement variation in the Old World (e.g. Dibble, 1984, 1987, 1995; Gordon, 1993; Hiscock, 1996; Holdaway et al., 1996; Kuhn, 1992, 1995; McPherron, 1994, 2000; Neeley \& Barton, 1994; Rolland \& Dibble, 1990), but also because reduction models have been successfully applied to many late-occurring implements types in Australia including tulas (Cooper, 1954; Hiscock \& Veth, 1991), bifacial points (Hiscock, 1994a), ground cylindro-conical artefacts (Cundy, 1985), burinates (Hiscock, 1993), and "core tools" (McNiven \& Hiscock, 1988). Applying these reduction perspectives, in the form proposed above, to the majority of implements in Australian assemblages would have significant implications. For instance, if morphological variation is a product of reduction, then implement production may well be a casual, mechanical process rather than the result of shaping specific 
tools to a preconceived design. We demonstrate the applicability of this reduction model by examining the assemblage from one of the classic sites at which early industries were defined, Capertee 3, a sandstone rockshelter in the Blue Mountains west of Sydney.

\section{Variability in the Capertian}

The great temporal marker of southern Australia has been the backed artefact, a "microlith" implement that first appears in sites in the terminal Pleistocene or early Holocene (Hiscock \& Attenbrow, 1998), but only becomes proportionately frequent in assemblages during the mid-Holocene (Hughes \& Djohadze, 1980; Attenbrow, 1987; Hiscock, 1994b). The period in which backed artefacts dominated assemblages has conventionally been labeled the "Bondaian". In eastern Australia the first evidence of "Pre-Bondaian", in the form of assemblages without backed artefacts stratigraphically below Bondaian assemblages, was obtained by Fredrick McCarthy during his excavations in the Capertee Valley (McCarthy, 1964). The key site in his investigations was the Capertee 3 rockshelter, which yielded a large collection of implements. McCarthy employed this collection to typify the assemblage characteristics of the early phase, which he labelled the "Capertian". His typological analysis of the Capertian centred on a description of dorsally retouched flakes he described variously as scrapers, knifes and saws. Given the formative role played by this collection, and McCarthy's analysis of it, in shaping ideas about assemblage variation in Australia we have selected it as a study of the variation created by differing degrees of reduction.

Capertian "scrapers" vary noticeably in size, with complete specimens having lengths of $37 \cdot 01 \pm$ $13.81 \mathrm{~mm}$ and widths of $37.91 \pm 14.71 \mathrm{~mm}(N=54)$. These scrapers also differ in terms of the retouch they display (see examples in Figure 1). McCarthy's Capertian "scraper" classes were constructed using two variables: position and number of retouched edges, and retouched edge shape. McCarthy (1964) described the number of edges containing retouch using categories such as "side" or "end" for those flakes with one retouched margin, "side and end" or "double side" for those with two retouched margins, and "double side and end" or "semi-discoidal" for those with three retouched margins. McCarthy simultaneously described the shape of retouched edges using labels such as "notched", "concave", "straight", "convex", "nosed", "semi-discoidal", and "discoidal". These descriptive categories were combined in ad-hoc ways rather than in an explicit and systematic framework. Consequently McCarthy (1964: 246) produced labels such as "concave and nosed double side and end scraper" and "side scraper with convex working edge". Employing these two dimensions of implement morphology this procedure yielded a bewildering diversity of implement classes.
In characterizing assemblage variation in this way McCarthy concentrated on differences in the position and shape of retouched edges, with little or no attention paid to blank form. For this reason the differences between implement forms in the Capertian of Capertee 3 reflect only retouching, rather than technological differences in flake production, and are therefore susceptible to re-interpretation in terms of the amount of retouching. Conventional typological classifications have acted as though differences in retouch between classes were qualitative and discontinuous, although difficulty in distinguishing the class boundaries may suggest variation is continuous. The proposition being tested in this paper is that the differences are substantially quantitative, representing differences in the extent of reduction.

\section{Capertian reanalysis}

McCarthy's classification of each of the Capertee 3 implements is not preserved in the museum collections, as the specimens have been disassociated with his labels over the last forty years. We therefore do not seek to test a reduction model by statistical comparisons of the different implement types as Dibble $(1984,1987)$ has done on European collections. Instead, for the reasons discussed above, we use a number of quantitative measures to evaluate the relationship of retouch characteristics and extent of reduction. After excluding specimens that are technically cores or unmeasureable heat shattered fragments, we are left with 98 dorsally retouched flakes that McCarthy had classified as Capertian implements. Retouch on these specimens is both marginal and steep. For this reason we consider that Kuhn's (1990) index of reduction is an appropriate measure of the extent of retouching. We applied Kuhn's measurement at three places, evenly spaced, along the longest retouched edge of each specimen (see Figure 2), and calculated the average: a value we refer to as the "Average Kuhn reduction index". For the retouched flakes in Capertian levels of Capertee 3, as defined by McCarthy, this index varied between $0 \cdot 12$ and $0.93(\bar{x}=0.48$, s.D. $=0.23)$. Since Kuhn's index has the benefit of ranging between 0 and 1 , it is clear that the specimens at Capertee 3 include those that had been minimally reduced as well as those that were far more highly reduced.

We take values of this index to be positively related to the intensity of retouching for reasons explored by Kuhn (1990). Furthermore in the Capertee 3 assemblage there is a positive association between the measured index and other characteristics of retouching that could also be expected to increase as reduction proceeds. For instance, there is a strong correlation between this index and the length of retouch on each specimen (Table 1). This relationship holds for all dorsally retouched flakes in the Capertian levels, complete and incomplete, and for unbroken specimens alone. We suggest this relationship exists because the 

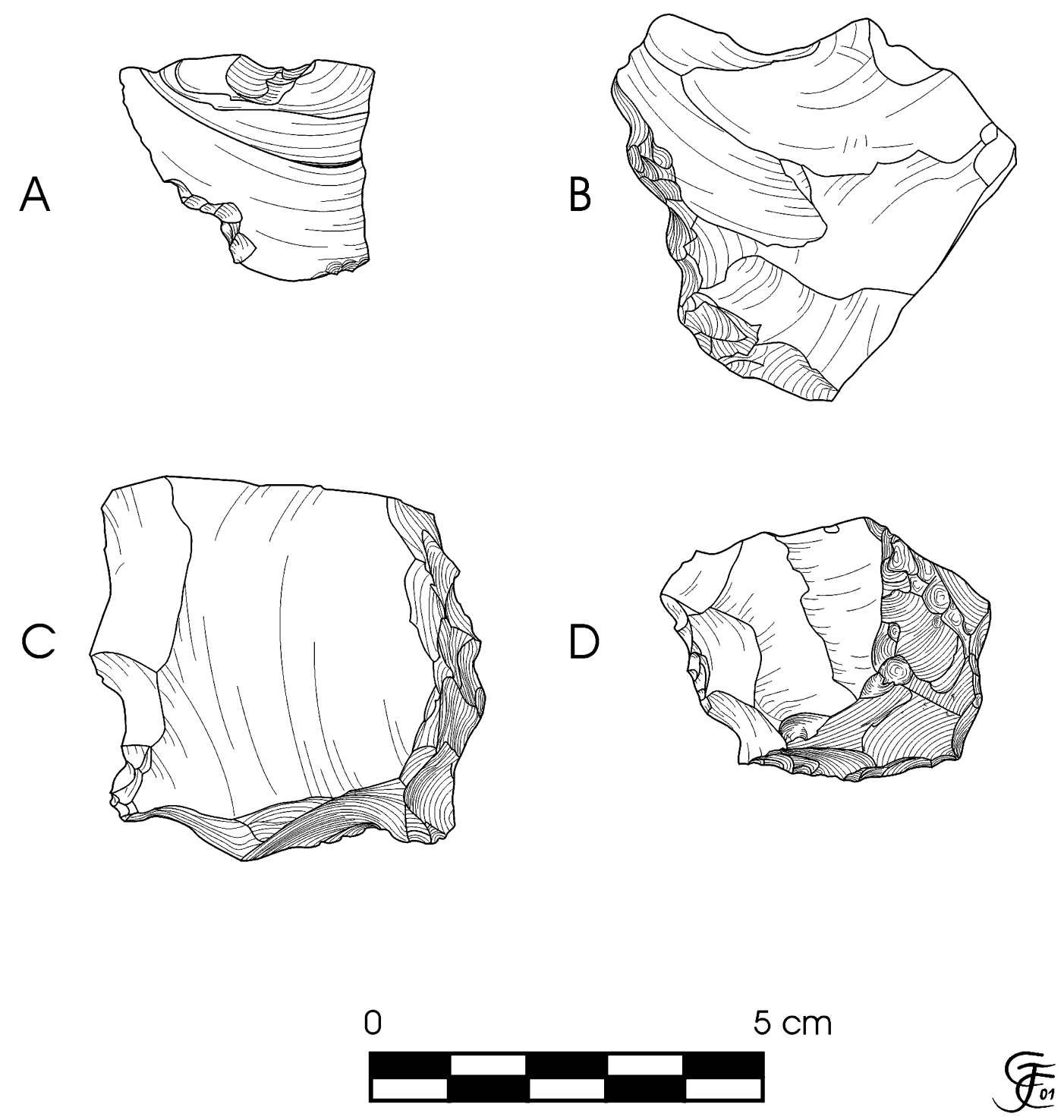

Figure 1. Examples of four retouched flakes from Capertee 3. A is ESP1084 (reduction index 0.40, curvature index -0.14), B is ESP1078 (reduction index $0 \cdot 47$, curvature index 0.05), C is ESP1225 (reduction index 0.62, curvature index 0.80), D is ESP1220 (reduction index 0.90, curvature index 1·11).

values of both variables are higher on more heavily retouched specimens.

Examining retouch as a proportion of flake margin can test this interpretation. If the length of retouch on a flake increases as reduction proceeds then it can be predicted that retouch scars may also extend further around the perimeter of the flake margins as retouch continues. While patterns of retouching such as deep notching to restricted parts of the flake will not conform to that prediction, revealing that alternative reduction strategies exist, the correlation between the
Average Kuhn reduction index and retouch length indicates that in the Capertee assemblage extended retouch involves lateral shifts in the position of retouching. This can be evaluated by calculating the extent of retouch as a fraction of the ventral surface perimeter, giving a "retouch perimeter index" that will range between 0 for unretouched flakes and 1 for flakes with all flake margins entirely retouched. The perimeter of the ventral surface of unbroken retouched flakes was calculated using SigmaScan Pro software to measure the calibrated distance along the diagonals of 


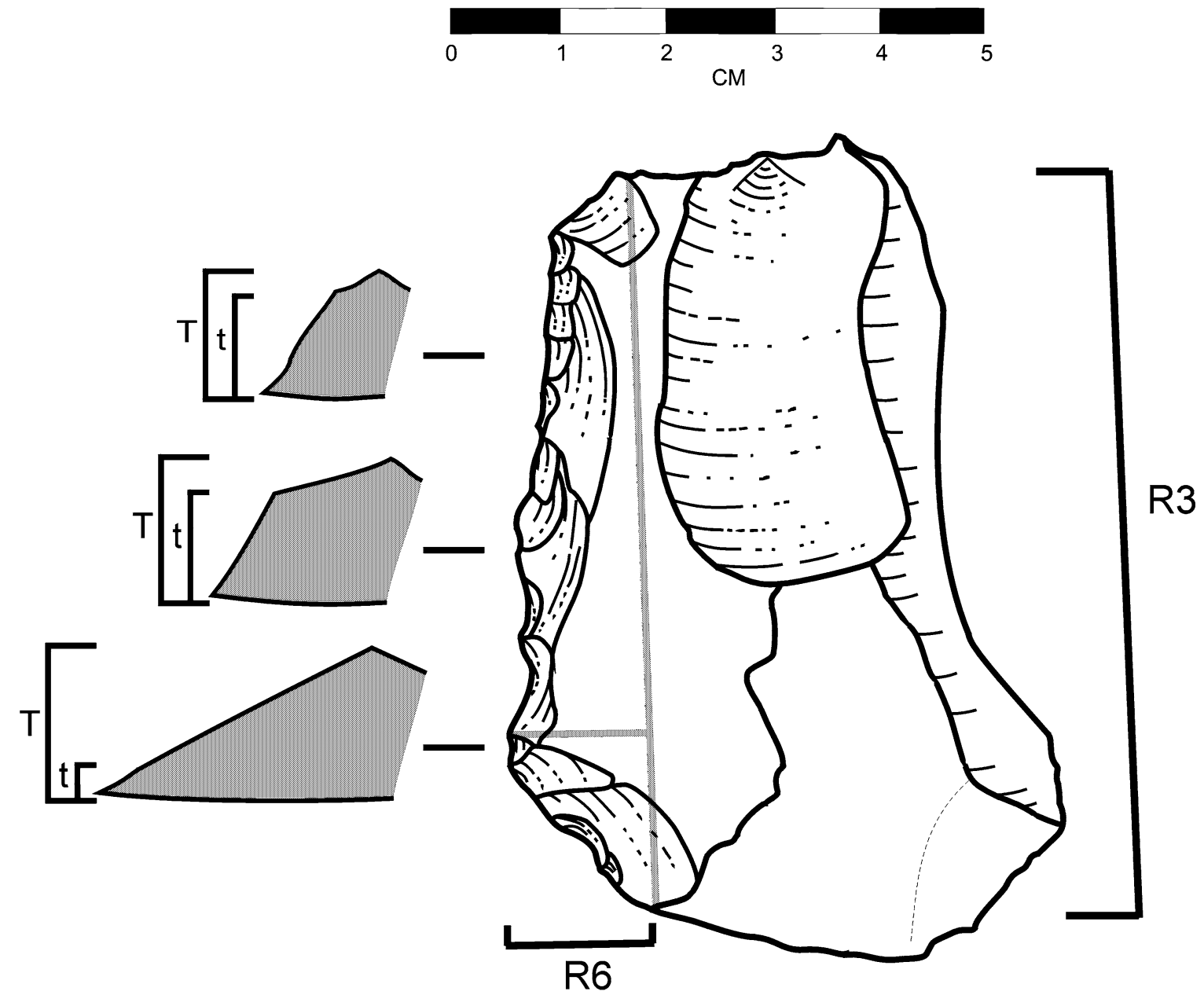

Figure 2. Illustration of a retouched flake from Capertee 3 (ESP1024, Square 9 Level G), showing the location of variables used in calculating the Index of retouch curvature and Average Kuhn reduction index.

the edge pixels of the digitized image of each specimen. This value was divided into the measured length of retouch to give a "retouch perimeter index" for each unbroken retouched flake. This index could be calculated for 48 specimens, yielding values ranging from a barely retouched 0.06 to an extensively retouched 0.77 $(\bar{x}=0 \cdot 27$, S.D. $=0 \cdot 16)$. As predicted a linear regression between Average Kuhn reduction index and the retouch perimeter index revealed these variables to be strongly correlated $\left(r=0 \cdot 88, r^{2}=0 \cdot 78, P<0 \cdot 001\right)$. This positive relationship indicates that in the Capertian assemblage greater amounts of retouching typically involved reduction of additional portions of the flake

Table 1. Correlation statistics for retouch length and the average Kuhn reduction index

\begin{tabular}{lccccc}
\hline & Pearson's $r$ & $r^{2}$ & $F$ & Significance & $N$ \\
\hline All specimens & 0.811 & 0.658 & 178.534 & $<0.001$ & 94 \\
Complete only & 0.821 & 0.675 & 120.333 & $<0.001$ & 59 \\
\hline
\end{tabular}

margins as well as additional flaking to previously retouched portions.

If this interpretation is correct, and the length of margin that is retouched increased as reduction proceeded, then at least the aspects of McCarthy's classification that are based on the number of retouched edges is likely to vary with the intensity of reduction. We have measured the location of retouch on the Capertian flakes by recording the presence or absence of retouch in eight notional sections (proximal end, distal end, and for each margin the proximal, medial, and distal thirds). Each implement could have between one and eight of these sections retouched. The number of retouched sections shows a strong linear relationship with the Average Kuhn reduction index (Table 2), such that the extent of reduction explains more than $70 \%$ of variation in the number of retouched sections. Again this relationship is maintained even if broken specimens are excluded from the analysis. This pattern is congruent with the hypothesis that as reduction proceeds additional sections of the flake margin are retouched 
Table 2. Correlation statistics for number of retouch segments and the average Kuhn reduction index

\begin{tabular}{lccccc}
\hline & Pearson's $r$ & $r^{2}$ & $F$ & Significance & $N$ \\
\hline All specimens & 0.840 & 0.705 & 217.331 & $<0.001$ & 92 \\
Complete only & 0.852 & 0.729 & 153.199 & $<0.001$ & 59 \\
\hline
\end{tabular}

In fact it appears that the expansion of retouch around the perimeter of a flake proceeded in a regular way. Retouch is more common on the distal than the proximal portions, and more frequent on left than right margins. Even on specimens with comparatively low reduction indices the distal section of the left lateral margin is frequently retouched to the same level as is observed on specimens with far higher reduction index values (Figure 3). All other sections show a substantial increase in retouch frequency with greater reduction. Our interpretation of this pattern is that flake retouching often began with blows to the distal portion of the left lateral margin and/or distal end, and spread to other sections of the flake as reduction progressed. However the location of initial blows and sequence of retouch undoubtedly varies between specimens. This accounts for specimens that McCarthy described variously as side scrapers or end scrapers having low Kuhn reduction indices.

If the proposition that increased retouching lengthens the retouched edge and involves retouching a second or third margin is correct, then it could be predicted that extended reduction may change the curvature of the retouched edge. This brings us to the second aspect of the conventional typology employed by McCarthy to describe implement variation in the Capertian: shape of retouched edges. We have

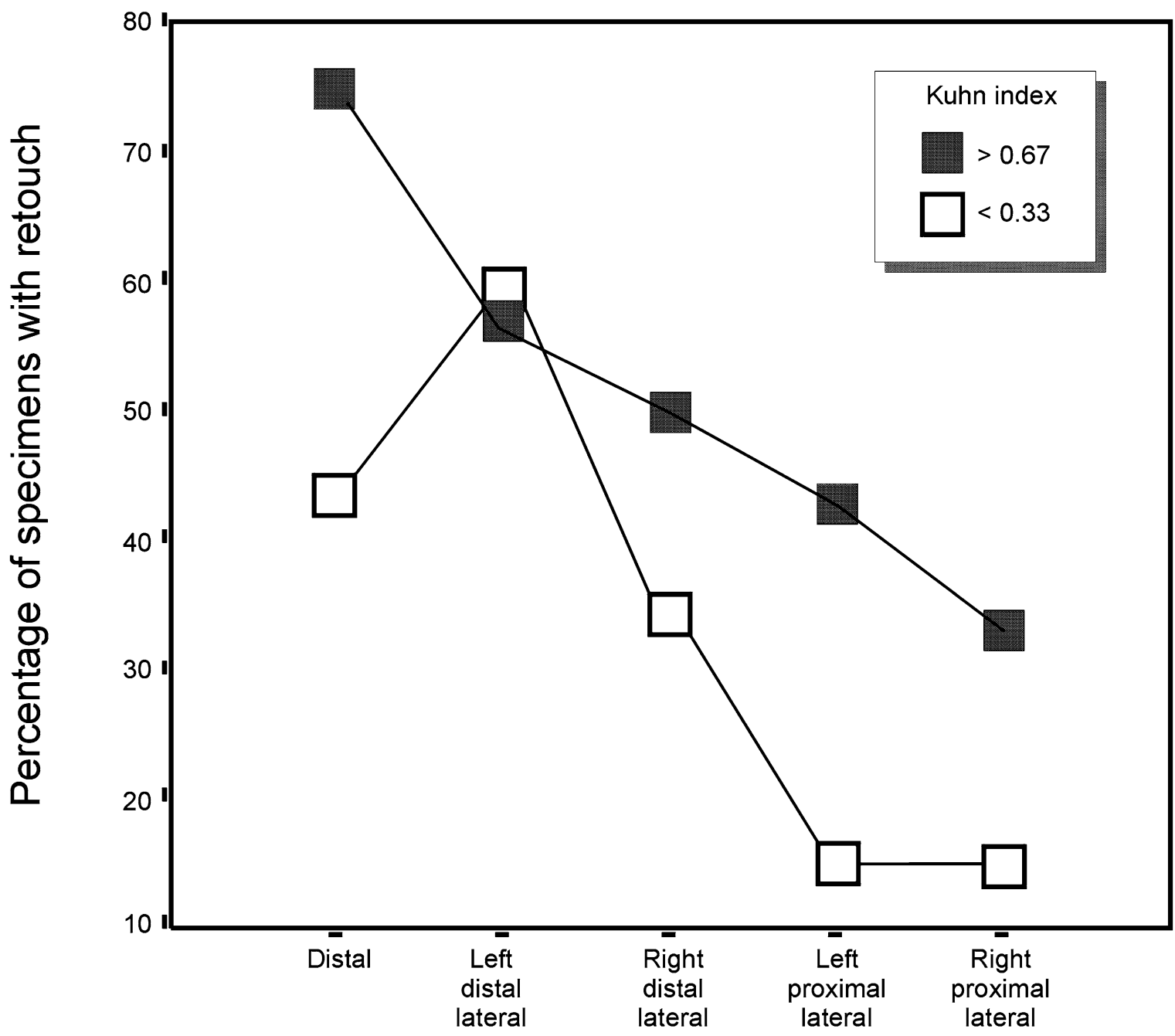

Flake sections

Figure 3. Relationship of the frequency of retouch at different location on the flake and Average Kuhn reduction index. 


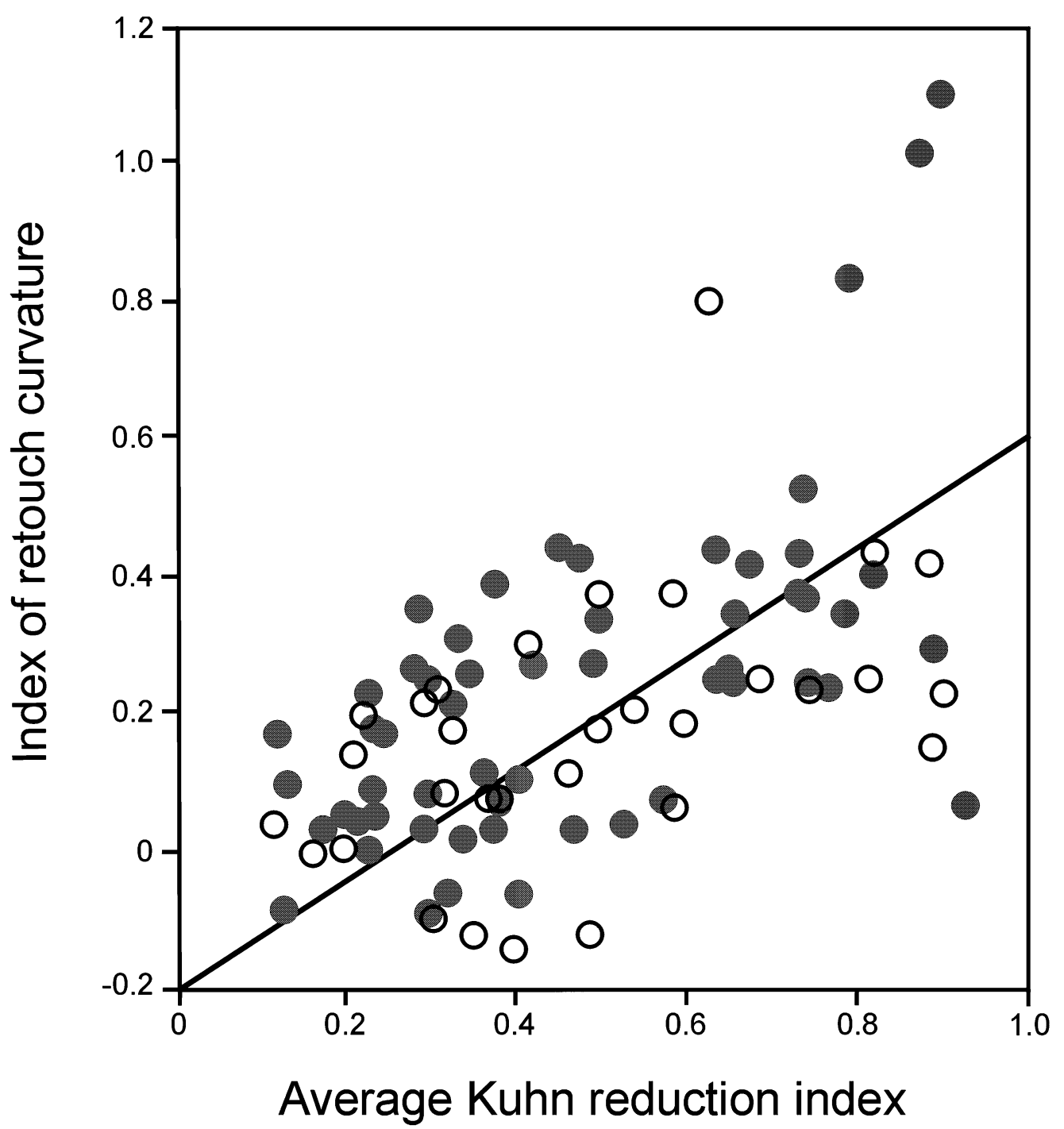

Figure 4. Scatterplot of the relationship between a measure of reduction intensity and a measure of retouch curvature. Solid data points are complete specimens.

developed a simple quantitative measure of retouched edge shape by a calculation (R3/R6) which expresses the extent of concavity or convexity of the edge relative to the distance between the ends of the retouch (Figure 2). This "Index of retouch curvature" is 0 for a straight edge, negative for concave edges, and positive for convex edges. The larger the positive value the more convex is the edge. For the Capertian assemblage this index ranged from a slightly concave value of $-0 \cdot 14$ through to highly convex value of $1 \cdot 11(\bar{x}=0 \cdot 21$, S.D. $=0 \cdot 22, N=98)$. Excluding broken specimens makes almost no difference to these statistics.

The relationship between this index of retouch curvature and the Average Kuhn reduction index is shown in Figure 4, along with a regression line describing the positive covariation. The strength of this relationship is measured by coefficients for the entire sample and for complete specimens alone (Table 3). In this analysis the extent of reduction explains more than $80 \%$ of variation in shape of the retouched edge as we have measured it. We suggest this relationship indicates that retouch curvature increases as the piece is retouched because (a) retouch extends to new portions of the flake thereby increasing the R6 value and/or (b) retouching decreases the $\mathrm{R} 3$ value. Retouch, beginning in a restricted area of one margin, typically produced a

Table 3. Correlation statistics for curvature index and the average Kuhn reduction index

\begin{tabular}{lrcccc}
\hline & Pearson's $r$ & $r^{2}$ & $F$ & Significance & $N$ \\
\hline All specimens & 0.904 & 0.818 & $390 \cdot 562$ & $<0.001$ & 88 \\
Complete only & 0.910 & 0.828 & 274.132 & $<0.001$ & 58 \\
\hline
\end{tabular}



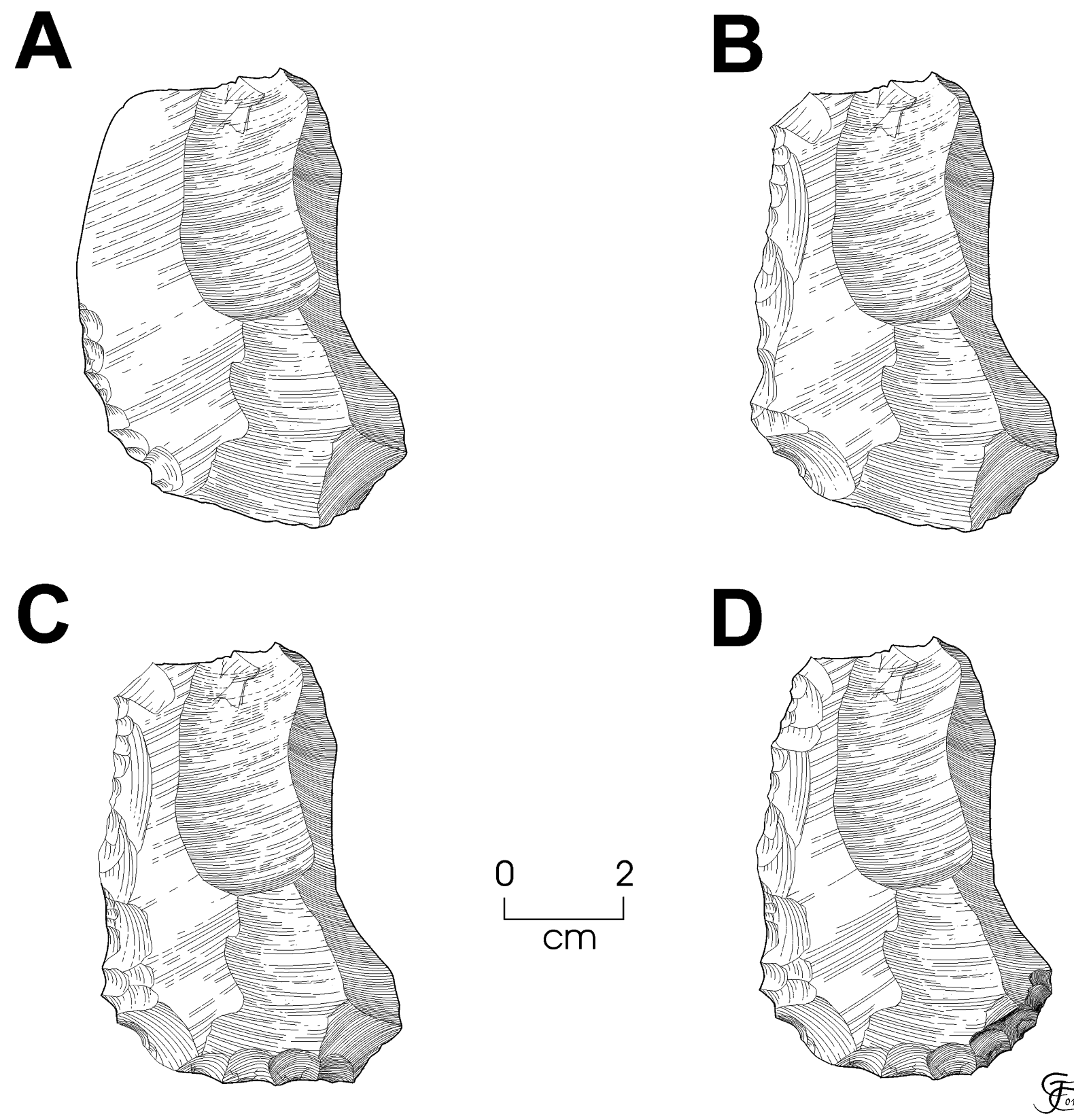

Figure 5. Illustration of typical reduction continuum inferred at Capertee 3. A has Curvature Index of $0 \cdot 15$ and Reduction Index of $0 \cdot 38$, B has Curvature Index of 0.27 and Reduction Index of $0 \cdot 65$, C has Curvature Index of 0.38 and Reduction Index of 0.74 , and D has Curvature Index of 0.57 and Reduction Index of 0.92.

slightly concave or convex edge, but as reduction proceeded and retouching was carried out on adjacent margins of the flake the retouched edge became progressively more convex until semi-discoidal specimens retouched on three or four margins were produced. This process of retouching at Capertee 3 is illustrated in Figure 5, which uses values predicted by the all of the regression analyses discussed here to give an interpretation of the typical morphological changes that took place as reduction proceeded (see also examples in Figure 1).

\section{Discussion}

Two inferences can be drawn from these analyses about the differences between retouched flakes, often called "scrapers", that McCarthy recovered from the Capertian levels of Capertee 3. Both inferences may well have broader applicability to knapping technologies in other times and places, elsewhere in the world as well as at different locations in Australia. Firstly, variation in retouch characteristics, here measured in terms of curvature and size of the 
retouched edge, is continuous rather than discontinuous. This is not an observation that the typological system previously employed had been capable of making. Secondly, morphological variation in retouched flakes, and hence the difference between perceived implement types, is largely related to differences in the extent of reduction. This proposition was established by cross-checking relationships between morphological features and a number of measures of reduction. The results of analyses presented are consistent with the reduction model outlined above, and less readily explicable in terms of a series of discrete tool designs. Note that this conclusion does not imply that implements always obtain a particular morphology after a fixed amount of retouching, or that a single, invariable sequence of reduction was being employed by knappers at Capertee 3. Nevertheless, the results strongly indicate that extent of reduction is probably the dominant factor creating variation amongst the Capertian implements.

Although these findings are derived from the assemblage at only one site it is anticipated that a model of morphological variability in "scrapers" reflecting the intensity of reduction may be broadly applicable to assemblages which predate the introduction of backed artefacts across much of Australia. If this can be demonstrated it will assist in explaining perceived spatial and chronological trends in Pleistocene and early Holocene Australian assemblages (e.g. Lorblanchet \& Jones, 1979; Kohen et al., 1981; Lampert, 1981). For instance, one purported trend inferred through typological analyses is an increase through time in the proportion of smaller and more "neatly" prepared implements within assemblages. If these kinds of morphologies represent more extensively retouched forms, as they do at Capertee, then a chronological trend emphasizing them might be partly be understood in terms of factors that encourage more extended retouching. Such a perspective on temporal trends compliments investigations into the relationship of assemblage composition with residential mobility (McNiven, 1994, 2000) and raw material supply (Hiscock \& Allen, 2000), relationships which are the subject of current interest in Australia (Hiscock \& Clarkson, 2000). The recognition that much Australian typological variability is explicable in these terms, rather than as a product of style or function, is consistent with recent conclusions about Middle Palaeolithic assemblages (e.g. Dibble \& Rolland, 1992). Parallels between early Australian typological patterns and those of the European Middle Palaeolithic have been noted before (e.g. Jones, 1977), and are especially ironic in view of the analogical uses to which Aboriginal ethnography was put by nineteenth century archaeologists.

Much debate has been fostered by the recognition that some assemblages of stone artifacts display continuous morphological variation and that nonarbitrary divisions that might be considered to be specific tool designs do not exist. The interpretation of Middle Palaeolithic implement variation has been the focus of this debate, with considerable emphasis being given to the implications of distinct types for our understanding of conceptualization of early hominids. One manifestation of this debate is the degree to which Upper Palaeolithic assemblages are distinguished from the Middle and Lower Palaeolithic ones by the presence of what Mellars $(1989,1991,1996)$ termed "imposed form" in the flaked implements. The existence of standardized implement morphologies has sometimes been interpreted as an indicator that prehistoric knappers conceived of distinctive tool "concepts" (Mellars, 1989, 1996), an argument developed with reference to ethnographic models of contemporary hunter-gatherers. A similar proposition is embedded in the use of the number of implement types as a measure of the cognitive complexity of early hominids (e.g. Foley, 1996; Wynn, 1999; Wynn \& Tierson, 1990). These propositions have been maintained, even though reduction models may be capable of explaining patterned morphological variation in lithic assemblages without implying mental templates (Dibble, 1989). This debate has expanded with the development of coherent models of continuous variation in Lower Palaeolithic assemblages lending themselves to arguments that conventional "types" in early assemblages may merely be a product of arbitrary classificatory divisions (e.g. McPherron, 2000), what Noble \& Davidson (1996: 168) have called the "finished artefact fallacy". Similar arguments have also been advanced, albeit in more limited ways, for more recent lithic assemblages from the Old World (e.g. Hiscock, 1996; Holdaway, 1991; Neeley \& Barton, 1994). The investigation presented here adds to the geographical range of these varied reduction models, and can be used to provide a new dimension to discussions of their implications.

What we have shown in this paper is that at Capertee 3, the "type" site originally used to define the nature of "early" Australian assemblages, there was a stoneworking technology structured around continuous reduction of retouched flakes without distinct evidence of "imposed form". This conclusion extends to all stone artifacts known at Capertee 3 during the terminal Pleistocene and early Holocene; items such as edge-ground axes are not known in the southern parts of Australia at that time (Attenbrow, 1987: 119, 121-122; Hiscock, 1994b; White \& O'Connell, 1981: 125-128). Continuous variation in "scraper" retouch in response to the intensity of retouch, may well be one archaeological signature of the profane and pragmatic, even "casual", approach to knapping ethnographically seen amongst Aboriginal people (see Hayden, 1977; Hiscock, 1998). Coming as they do from societies for which we have abundant archaeological evidence of mobile and parietal art, complex burials, and multi-component organic artifacts these findings indicate that for modern humans there is no necessary 
relationship between those other aspects of life and whether or not a stoneworking technology was structured around continuous reduction. Hence our demonstration of this reduction model at Capertee reveals that continuous variation without distinct evidence of "imposed form" is a pattern present in both early and late stoneworking technologies, in artefacts produced by both extinct and extant hominids, and should not be taken to represent an "archaic" cognitive state. This conclusion implies that a technological strategy of continuous reduction may have more proximate causes, technological and/or economic and/or social, rather than being linked to particular cognitive capacities or processes. Developing a better understanding of lithic technologies producing continuous morphological variation will therefore be assisted by detailed investigations into their technical and socioeconomic contexts and roles. In this way clarifying the factors determining morphological variation in early Australian assemblages, which were created in the comparatively recent past by modern humans, may assist in comprehending the patterning of assemblages created by hominids in more remote times.

\section{Acknowledgements}

We thank the Trustees of the Australian Museum for access to the Capertee collection. We acknowledge the assistance of Leanne Brass in obtaining access to archaeological material. The bulk of the recording was carried out during September 2000 at the Australian Museum, which provided laboratory space and facilities. Figures 1 and 5 were drawn by Chris Clarkson. Wilfred Shawcross was of invaluable assistance in preparing the other illustrations. We thank a number of people for discussion of the ideas contained in this report: Chris Clarkson, Steven Kuhn, Harold Dibble, Robin Torrence and Peter White.

\section{References}

Attenbrow, V. J. (1987). The Upper Mangrove Creek Catchment: a study of quantitative changes in the archaeological record. Unpublished PhD dissertation, University of Sydney.

Barton, C. M. (1988). Lithic variability and Middle Paleolithic Behavior. BAR International Series 408.

Bowdler, S. (1981). Stone tools, style and function: evidence from the Stockyard Site, Hunter Island. Archaeology in Oceania 16, 64-69.

Bowler, J. M., Jones, R., Allen, H. \& Thorne, A. (1970). Pleistocene Human remains from Australia: a living site and human cremation from Lake Mungo, western New South Wales. World Archaeology 2, 39-60.

Clarkson, C. (2002). An Invasiveness Index. Journal of Archaeological Science 29, 65-75.

Clegg, J. K. (1977). The four dimensions of artificial variation. In (R. V. S. Wright, Ed.) Stone Tools as Cultural Markers: Change, Evolution and Complexity. Humanities Press Inc., pp. 60-66.

Cooper, H. M. (1954). Material culture of Australian Aborigines Part 1. Progressive modification of a stone artefact. Records of the South Australian Museum 11, 91-7.
Cundy, B. J. (1985). The secondary use and reduction of cylindroconical stone artifacts from the Northern Territory. The Beagle $\mathbf{2}$, 115-127.

Dibble, H. L. (1984). Interpreting typological variation of Middle Paleolithic scrapers: function, style, or sequence of reduction? Journal of Field Archaeology 11, 431-436.

Dibble, H. L. (1987). The interpretation of Middle Paleolithic scraper morphology. American Antiquity 52, 109-117.

Dibble, H. L. (1989). The implications of stone tool types for the presence of language during the Lower and Middle Paleolithic In (P. Mellars \& C. Stringer, Eds) The Human Revolution: Behavioural and Biological Perspectives on the Origins of Modern Humans. Edinburgh: Edinburgh University Press, pp. 415-432.

Dibble, H. L. (1995). Middle Paleolithic scraper reduction: background, clarification, and review of evidence to date. Journal of Archaeological method and theory 2, 299-368.

Dibble, H. L. \& Rolland, N. (1992). On assemblage variability in the Middle Paleolithic of Western Europe: history, perspectives, and a new synthesis. In (H. L. Dibble \& P. Mellars, Eds) The Middle Paleolithic: adaptation, behavior, and variability. University Museum, University of Pennsylvania, pp. 1-28.

Flenniken, J. J. (1985). Stone tool reduction techniques as cultural markers. In (M. G. Plew, J. C. Woods \& M. G. Pavesic, Eds) Stone tool analysis: essays in honor of Don E. Crabtree. Albuquerque: University of New Mexico Press, pp. 265-276.

Foley, R. A. (1996). Measuring cognition in extinct Hominids. In (P. Mellars \& K. Gibson, Eds) Modelling the early human mind. McDonald Institute for Archaeological research, pp. 57-65.

Geneste, J-M. (1989). Economie des resources lithiques dans le Mousterien de sud-ouest de la France. I. In (M. Otte, Ed.) L'Homme de Neandertal Volume 6. La Subsistance. Etudes et Recherches Archeologiques de L'Universite de Liege No. 33.

Gordon, D. (1993). Mousterian tool selection, reduction, and discard at Ghar, Israel. Journal of Field Archaeology 20, 205-218.

Hayden, B. (1977). Stone tool functions in the Western Desert. In (R. V. S. Wright, Ed.) Stone Tools as Cultural Markers: Change, Evolution and Complexity. Humanities Press, pp. 178-188.

Hiscock, P. (1993). Bondaian technology in the Hunter Valley, New South Wales. Archaeology in Oceania 28, 64-75.

Hiscock, P. (1994a). The end of points. In (M. Sullivan, S. Brockwell $\&$ A. Webb, Eds) Archaeology in the North. NARU, Australian National University, pp. 72-83.

Hiscock, P. (1994b). Technological responses to risk in Holocene Australia. Journal of World Prehistory 8, 267-292.

Hiscock, P. (1996). Transformations of Upper Palaeolithic implements in the Dabba industry from Haua Fteah (Libya). Antiquity 70, 657-664.

Hiscock, P. (1998). Revitalising artefact analysis. In (T. Murray, Ed.) Archaeology of Aboriginal Australia. Sydney: Unwin and Allen, pp. 257-265.

Hiscock, P. (2002). Looking the other way. A materialist/ technological approach to classifying tools and implements, cores and retouched flakes. In (S. McPherron \& J. Lindley, Eds) Tools or Cores? The Identification and Study of Alternative Core Technology in Lithic Assemblages. University of Pennsylvania Museum.

Hiscock, P. \& Allen, H. (2000). Assemblage variability in the Willandra Lakes. Archaeology in Oceania 35, 97-103.

Hiscock, P. \& Attenbrow, V. (1998). Early Holocene Backed Artefacts from Australia. Archaeology in Oceania 33, 49-63.

Hiscock, P. \& Clarkson, C. (2000). Analysing Australian stone artefacts: An agenda for the twenty first century. Australian Archaeology 50, 98-108.

Hiscock, P. \& Veth, P. (1991). Change in the Australian Desert Culture: a reanalysis of tulas from Puntutjarpa. World Archaeology 22, 332-345.

Holdaway, S. J. (1991). Resharpening reduction and lithic assemblage variability across the Middle to Upper Paleolithic Transition. Unpublished $\mathrm{PhD}$ dissertation, University of Pennsylvania.

Holdaway, S., McPherron, S. \& Roth, B. (1996). Notched tool reuse and raw material availability in French Middle Paleolithic sites. American Antiquity 61, 377-387. 
Holmes, W. H. (1890). A quarry workshop of the flaked stone implement makers in the District of Columbia. American Anthropologist 3, 1-26.

Hughes, P. J. \& Djohadze, V. (1980). Radiocarbon dates from archaeological sites on the south coast of New South Wales and the use of Depth/Age curves. Occasional Papers in Prehistory. Department of Prehistory, Australian National University.

Jones, R. (1977). The Tasmanian paradox. In (R. V. S. Wright, Ed.) Stone Tools as Cultural Markers: Change, Evolution and Complexity. Humanities Press Inc., pp. 189-204.

Kohen, J., Stockton, E., Williams, M., Cowling, G., Glodberg, P. Scott-Virtue, L. \& Sumner, C. (1981). Where plain and plateau meet: recent excavations at Shaws Creek Rockshelter, eastern New South Wales. Australian Archaeology 13, 63-68.

Kuhn, S. (1990). A geometric index of reduction for unifacial stone tools. Journal of Archaeological Science 17, 585-593.

Kuhn, S. (1992). Blank form and reduction as determinants of Mousterian scraper morphology. American Antiquity 57, 115-128.

Kuhn, S. L. (1995). Mousterian Lithic Technology. Princeton University Press.

Lampert, R. J. (1971). Burrill Lake and Currarong. Terra Australis 1. Department of Prehistory, Australian National University.

Lampert, R. (1981). The Great Kartan Mystery. Terra Australis 5. Canberra: Australian National University.

Leroi-Gourhan, A. (1956). La galerie mousterienne de la grotte du Renne (Arcy-sur-Cure, Yonne). Congres Prehistorique de France, Poitiers-Angouleme, 15e session, pp. 676-691.

Leroi-Gourhan, A. (1966). La Prehistorie. University of France Press.

Lorblanchet, M. \& Jones, R. (1979). Les premieres fouilles a Dampier (Australie occidentale), et leur place dans l'ensembl australien. Bulletin de la Societe Prehistorique Francaise 76, 463-487.

McCarthy, F. D. (1948). The Lapstone Creek excavation: two culture periods revealed in eastern New South Wales. Records of the Australian Museum 22, 1-34.

McCarthy, F. D. (1949). The prehistoric cultures of Australia. Oceania 19, 305-19.

McCarthy, F. D. (1958). Culture succession in south eastern Australia. Mankind 5, 177-190.

McCarthy, F. D. (1963). Nomenclature of Australian stone implements: the 1946 classification. AIAS conference on nomenclature of implements and culture 25-28th April. Typescript.

McCarthy, F. D. (1964). The archaeology of the Capertee Valley, N.S.W. Records of the Australian Museum 26, 197-246.

McCarthy, F. D. (1967). Australian Aboriginal Stone implements. Sydney: Australian Museum Trust.

McCarthy, F. D., Brammell, E. \& Noone, H. V. V. (1946). The Stone Implements of Australia. Memoirs of the Australian Museum 9, $1-94$.
McNiven, I. J. (1994). Technological organization and settlement in southwest Tasmania after the glacial maximum. Antiquity 68, 75-82.

McNiven, I. J. (2000). Backed to the Pleistocene. Archaeology in Oceania 35, 48-52.

McNiven, I. \& Hiscock, P. (1988). Small unifacial pebble cores from Fraser Island, Southeast Queensland. Queensland Archaeological Research 5, 161-165.

McPherron, S. P. (1994). A reduction model for variability in Acheulian biface morphology. Unpublished $\mathrm{PhD}$ dissertation, University of Pennsylvania. Philadelphia.

McPherron, S. P. (2000). Handaxes as a measure of the mental capabilities of Early Hominids. Journal of Archaeological Science 27, 655-663.

Mellars, P. (1989). Technological changes across the Middle-Upper Palaeolithic transition: technological, social, and cognitive perspectives. In (P. Mellars \& C. Stringer, Eds) The Human revolution: behavioural and biological perspectives on the origins of modern Humans. Princeton University Press, pp. 338-365.

Mellars, P. (1991). Cognitive changes and the emergence of modern humans in Europe. Cambridge Archaeological Journal 1, 63-76.

Mellars, P. (1996). Symbolism, language, and the Neanderthal mind. In (P. Mellars \& K. Gibson, Eds) Modelling the early human mind. McDonald Institute for Archaeological research, pp. 15-32.

Mitchell, S. R. (1949). Stone-age craftsmen. Stone tools and camping places of Australian Aborigines. Melbourne: Tait Book Company.

Mulvaney, J. \& Kamminga, J. (1999). Prehistory of Australia. Allen and Unwin.

Neeley, M. P. \& Barton, C. M. (1994). A new approach to interpreting late Pleistocene microlith industries in southwest Asia. Antiquity 68, 275-288.

Noble, W. \& Davidson, I. (1996). Human evolution, language and mind. Cambridge University Press.

Odell, G. H. (2000). Stone tool research at the End of the Millennium: procurement and technology. Journal of Archaeological Research 8, 269-331.

Rolland, N. \& Dibble, H. L. (1990). A new synthesis of Middle Paleolithic assemblage variability. American Antiquity 55, 480-499.

Wheat, J. B. (1976). Artifact life histories: cultural templates, typology, evidence and inference. In (J. S. Raymond, B. Loveseth, C. Arnold \& C. Reardon, Eds) Primitive Art and Technology. University of Calgary, pp. 7-15.

White, J. P. \& O'Connell, J. F. (1982). A prehistory of Australia, New Guinea and Sahul. Academic Press.

Wynn, T. (1999). The evolution of tools and symbolic behaviour. In (A. Lock \& C. R. Peters, Eds) Handbook of Human Symbolic Evolution. Blackwell, pp. 263-287.

Wynn, T. \& Tierson, F. (1990). Regional comparison of the shapes of later Acheulian handaxes. American Anthropologist 92, 73-84. 